University for Business and Technology in Kosovo

UBT Knowledge Center

Nov 8th, 9:00 AM - 9:15 AM

\title{
Use of passive design features and simulation modeling to improve Energy Performance and reduce Environmental Impacts of Buildings in Kosovo
}

\author{
Ferhat Bejtullahu \\ University for Business and Technology, ferhat.bejtullahu@ubt-uni.net \\ Dukagjin Bakija \\ University for Business and Technology, ginbakija@gmail.com \\ Art Bejtullahu \\ University for Business and Technology, artbejtullahu@gmail.com
}

Follow this and additional works at: https://knowledgecenter.ubt-uni.net/conference

Part of the Architecture Commons

\section{Recommended Citation}

Bejtullahu, Ferhat; Bakija, Dukagjin; and Bejtullahu, Art, "Use of passive design features and simulation modeling to improve Energy Performance and reduce Environmental Impacts of Buildings in Kosovo" (2014). UBT International Conference. 7.

https://knowledgecenter.ubt-uni.net/conference/2014/all-events/7

This Event is brought to you for free and open access by the Publication and Journals at UBT Knowledge Center. It has been accepted for inclusion in UBT International Conference by an authorized administrator of UBT Knowledge Center. For more information, please contact knowledge.center@ubt-uni.net. 


\title{
Use of passive design features and simulation modeling to improve Energy Performance and reduce Environmental Impacts of Buildings in Kosovo
}

\author{
Ferhat Bejtullahu ${ }^{1}$, Dukagjin Bakija ${ }^{2}$, Art Bejtullahu ${ }^{3}$ \\ ${ }^{1}$ Faculty of Architecture, UBT in Prishtina, Kosovo \\ ferhat.bejtullahu@ubt-uni.net, ginbakija@gmail.com, artbejtullahu@gmail.com
}

\begin{abstract}
Building physics and climate adapted architectural design parameters such as site, building form, orientation, shading and envelope performance (including structures and openings), contributes a significant proportion towards the better energy performance and reduce environmental impact of buildings. Due to extensive demand of electricity derived from the widespread use of cooling and heating systems has necessitated evolution and incorporation of minimum energy performance requirements in design practice. Objective of this paper is to promote role of passive design features and energy simulation to the researchers, scientists and practitioners within planning, architecture construction industry. Jointly, all these three industries are experiencing an continues shift whereby the issues of sustainable environment, resource conservation and energy efficiency have gained vital importance. Findings from this research require cultural assimilation into planning and architecture (including curriculums), construction industry and building-owner decision making in Kosovo. In order to achieve strategies and implement new concept, it is important to address these issues with a sense of urgency.
\end{abstract}

Keywords: Passive design feature, simulation modeling, energy performance, environmental impact.

\section{Introduction}

One of the main characteristics of traditional buildings in Kosovo is that they are built with a deep understanding and respect for microclimate and neighborhood, but this tradition with microclimate and neighborhood approach is no longer found in the modern design buildings. The knowledge from traditional construction, which was fairly well adapted to the microclimate, is often lost or difficult to translate to modern techniques and society.

\subsection{Challenging environmental problem and research questions}

Buildings in Kosovo are often built without taking enough account of the microclimate. Factors such as the urban surroundings or site characteristics, orientation and architectural design of the building, choice of building materials, etc. are not given enough importance. Consequently buildings often have a poor indoor climate, which affects comfort, health and efficiency.

As living standards rise people want to install heating and cooling equipment to improve comfort. For buildings not adapted to the climate, the amount of energy to run the equipment, and its cost, will be excessively high, and it will have a harmful impact on the environment. A good, or at least acceptable, indoor climate can often be achieved with little or no extra input of energy. Apart from a general not implicated new norms and regulations, one reason why buildings are poorly adapted to the climate is lack of knowledge among planners, architects and environmentalists. The urban building stock in developing countries is predicted to more than double by 2030. Demand for energy services in buildings in developing countries will rise substantially in the next two decades, driven by population growth, urbanization, and increased and expanded wealth.

In recent years, the rapid economical growth in some of the heavily populated nations has stimulated the utilization of sustainable energy sources and energy conservation methodologies considering environmental protection. Globally, buildings are responsible for approximately $40 \%$ of the entire 
world's annual energy consumption. Most of this energy is for the provision of lighting, heating, cooling and air-conditioning. The increasing level of damage to the environment has created greater awareness at the international level, which resulted in the concept of green energy building in the infrastructural sector. Hence, the major focus of researchers, policy makers, environmentalists and building architects has been on the conservation of energy and its utilization in buildings.

According to de Schiller and Evans (2006)[1], the ability to design passive buildings or environmentally responsive buildings depends on the skills and ability of the architect to identify varied climatic parameters within a site, develop awareness of possible future modifications produced by introduction of new built form and use this potential during the design process at different scales of application.

The bases of data for this paper are the results of building physics course. The entire project included different locations of a house. The passive design approaches employed in the design of the house are discussed. The main approach adopted was a review of special building passive design features that have resulted from the building design that have been developed in response to the natural environmental conditions on different climatic regions. The identified passive design concepts were applied in the design of the house.

Research questions arising from lectures and literature survey are:

- How important are passive design tools of different (planning, construction and environmental) aspects for achieving better Energy Performance and reducing Environmental Impacts of Buildings in Kosovo climate?

- How important is simulation modeling in promoting and achieving better energy performance ?

- How to reduce the environmental footprint of the building?

\subsection{Objective}

Main objective of this paper is to define role of planners, architects and environmentalist in achieving comfort conditions in buildings by adopting passive techniques in Kosovo building industry. In this way we can help town planners and building designers to produce a comfortable and sustainable built environment. Role of urban and architectural design in achieving better Energy Performance in Buildings using Passive Design Features in Kosovo is very important. The emphasis is on energy performance and environmental impacts of buildings, as well as on the integration of measures of performance and impacts in the development of innovative architecture. The architecture firms need integrated practices and experts on building technology to judge the impact of architectural design decisions on building performance at the early stages of design. These architects will be able to oversee the engineering and detailing of the building at later stages of the design process to ensure that performance targets are documented and fulfilled. Architects and regulators not enough rely on computer simulations to improve building designs and determine if a building satisfies Kosovo energy regulations. Local regulation regulates technical specifications and other specifications of construction products used for building construction for the purpose of thermal energy saving and thermal protection.

The specific objective of this study is to present information about the climatic design of buildings today, using passive design features. It explains central concepts in climatic design and gives recommendations on how to carry out the design in different microclimates. The focus is at use of simulation modeling for identifying changes in the design elements that can improve energy performance and reduce environmental impact.

\subsection{Methodology and Approach}

The study was completed in three main phases. The first and third phases consisted of desk. The second phase was a field research that was held in Kosovo urban scale. The first phase defined the theoretical framework for this study. In addition, it identified the methodology of analysis and issues that were investigated in the case study-Kosovo. This phase, mainly a desk study, encompassed extensive literature reviews of books, journal papers, researches and documents to identify passive design tools that could be used for the context of Kosovo. The third phase comprised of a desk study for the second time to analyze and evaluate the data from the first and second phase studies using quantitative and qualitative methods. 
The work is based on:

- Gathering experiences of author's as a planner, designer, researcher, professor assistant off building physics in education system of Kosovo and environmental studies.

- Literature review on experiences in other regions,

- Combination of personal experiences and collected information.

Paper covers all natural processes and techniques without any form of energy input. In this paper, focus is made on the relationship between microclimate conditions (nature) and user's behavior that should be taken into account in architectural space and urban projects.

To analyze the impact of the climate on user's behavior at Kosovo urban space scale data are collected from:

- Microclimate at: http://www.weatherbase.com

- Behavior data using photo-video observations.

- Users climate perception using a interview.

The performance approach is more complicated but is used because offers considerable design flexibility. The performance approach requires an approved computer software program that models a proposed building, determines its allowed energy, calculates its energy use, and determines compliance with regulations. Compliance options such as window orientation, shading, thermal mass, zonal control, and house configuration are all considered in the performance approach.

In Kosovo regulations help to use prescriptive approach that offers relatively little design flexibility but is easy to use. This paper promote simulation modeling as a base for performance approach.

\section{Context, microclimate and comfort}

\subsection{Planning aspects}

Planning analysis, site analysis of the building site should be made to determine the following: Wind protection. Dense housing developments and proliferation of built structures in Kosovo do not leave a scope for choosing a portion of the site without wind protection. Generally, plots are not surrounded by open spaces or green spaces in Kosovo.

Shade from existing buildings and trees. Watson and Labs (1983) [7] recommend placing a building in such a way that it gets shading from existing trees and landmasses. As already mentioned above, surrounding buildings in Kosovo are at very close proximity to plots. Hence, buildings constructed get shade form existing landmasses in almost all cases. Buildings, however, do not get shade from surrounding trees due to the absence of green spaces. The above-mentioned criteria do not directly generate reductions in energy use. Instead, they provide air movement for ventilation if windbreaks are absent and help to keep buildings cool through the shade provided by surrounding buildings.

Building form. Compactness of the building minimizes the surface area of the building envelope, resulting in a reduction of the heat gain through the envelope. It might not be possible to design open, outward buildings in constricted sites as of Kosovo and where maximum utilization of land for profitability is the main objective.

Building orientation. Properly oriented buildings take advantage of solar radiation and prevailing wind. According to Gut and Ackerknecht (1993)[3], the longer axis of the building should lie along east-west direction for minimum solar heat gain by the building envelope. During last semester, we have experimented computational energy simulations to examine the effectiveness of passive climate control methods such as building orientation in buildings of different cities in globe. The passive design feature on orienting, as suggested is not always possible, especially due to actual orientation of the site, that is, when the site itself is longer on the west and east sides. Such cases are outside the influence of the developer and the architect.

Landscaping. Raeissi and Taheri (1999) [6] acknowledge the beneficial effects of trees. They state that plantation of trees can result in energy saving, reduction of noise and pollution, modification of 
temperatures and relative humidity and psychological benefits on humans. Their study on proper tree plantation for energy saving concludes that the cooling loads of a house can be reduced by $10 \%-40 \%$ by appropriate tree plantation. They also note that trees can act complementary to window overhangs, as they are better for blocking low morning and afternoon sun, while overhangs are better barriers for high noon sunshine. Even though appropriate tree plantation can bring significant amount of energy savings, this design principle can only be applicable in buildings of Kosovo if adequate space is left open either as a setback area or as designated green space.

\subsection{Construction aspect}

Building Energy Performance in EU and Republic of Kosovo

It is in Kosovo's best interest to be part of the modern world and EU membership is already recognized as a final aim for Kosovo citizens. The region faces many challenges in fulfilling the EU requirements and most of them will be in the field of environmental law.

The main regulatory instrument in the EU for undertaking the energy consumption of buildings is the Directive 2010/31/EU on the Energy Performance of Buildings. A proper implementation and enforcement of the Directive's provision will make an important contribution to improving the energy performance of buildings. Member States have minimum performance requirements for building insulation and ventilation that are defined in national building codes and regulation. Differences occur due to climate, construction techniques and culture.

In the first part is presented results from analyze of current state in housing construction sector from energy performance point of view.

According to the content proposal for Unified Construction Code, it is not foreseen to transpose Directive 2010/31/EU but areas to be covered by construction code.

Obligations and objectives are to be regulated by secondary legislation acts and not by the law directly. As the secondary legislation acts has not been developed yet, the overall Kosovo's National approach for the implementation of the EPBD has not been selected and defined.

Although specific laws, regulations, and practices differ among countries, the National Environmental Policy Act's (NEPA) unique procedural innovations have influenced the EIA procedures of many countries, including Kosovo.

These requirements will obviously impose substantial burdens on the Kosovo Government and local experts. An overall reform of environmental education in Kosovo is needed, especially in the field of environmental law, to provide the experts who can satisfy both the international community requirements and Kosovo citizens' expectation for the economic development, which will respect their rights to a clean and healthful environment.

Setting of minimum energy performance requirements are incorporated with current Technical regulation on thermal energy savings and thermal protection in building No.03/2009 (local regulations). These regulations are introduction of definitions from relevant European Standards into national regulations (incl. from EN 15603 and EN 15217) but these standards are not included.

Despite good laws and regulations regarding environmental impact and thermal energy savings, Kosovo as regional countries is suffering from no consideration of this laws and regulations during design, maintain and use of buildings. As reports Croatian newspaper "Jutarni List" of date13.09.2013 a package of laws, which have developed construction sector, owners of new homes built without facades in the future have to pay fines of 3,000 kuna per month (about 400 Euros), according to new laws that will come into force in Croatia.

Conclusions of this paper argues necessity of selection and description of new approach to be used from architects, especially involved in education process, for setting of minimum energy performance parameters and new concept of energy performance of buildings using Passive Design Features. The recent concept of energy performance of buildings attracted all the scientists and building architects to switch over from the present practice of active technological tools to ancient methods of passive methods in an efficient modern way, introducing an environmental law course to the Kosovo university system. 


\subsection{Environmental aspect}

Microclimate. When designing and building the general outdoor climate is to be regarded as a given condition, though there might be climate change over a long time, and that it may be possible to affect the microclimate by urban and building design. This section discusses the climatic elements and their effect on thermal comfort.

Climate is the average of the atmospheric conditions over an extended time over a large region. Smallscale patterns of climate, resulting from the influence of topography, soil structure, ground and urban forms, are known as microclimates. The principal parameters characterizing climate are air temperature, humidity, precipitation and wind.

The climate of cities differs from the climate of the surrounding rural areas, due mainly to the structure of cities and the heat released by vehicles. In general, the climate in cities is characterized by ambient temperatures, reduced relative humidity, reduced wind speed and reduced received direct solar radiation.

The microclimate of an urban area can be modified by appropriate landscaping techniques, with the use of vegetation and water surfaces, and can be applied to public places, such as parks, play-grounds and streets [2].

Table 1 Kosovo weather averages Source:

http://www.weatherbase.com/weather/city.php3?c=XK\&name=Kosovo at: 25.06.2014

\begin{tabular}{|c|c|c|c|c|c|c|c|c|c|c|c|c|c|c|}
\hline \multirow[b]{2}{*}{ Average Temperature (C) } & \multicolumn{14}{|c|}{ ANNUAL JAN FEB MAR APR MAY JUN JUL AUG SEP OCT NOV DEC YEARS \# CITIES } \\
\hline & 10.7 & $-0.5 \mid$ & 1.5 & 5.9 & 10.5 & 15.4 & $\mid 18.820 .8$ & 820.3 & 16.8 & 11.4 & 6.2 & 0.9 & 26 & 4 \\
\hline Average High Temperature (C) & 16 & 2.9 & 5.8 & 10.8 & 16.3 & 21 & 24.827 .4 & 427.1 & 23.3 & 17.5 & 10.8 & 4.2 & 26 & 4 \\
\hline Average Low Temperature (C) & 5.5 & -3.9 & -2.2 & 1.2 & 5.1 & 9.5 & 12.514 .1 & 113.6 & 10.5 & 6 & 2.1 & -2 & 26 & 4 \\
\hline Average Precipitation (mm) & 714.7 & 57.8 & 45.4 & 46.9 & 54.3 & 65.8 & $\mid 58.351 .2$ & 264.9 & 45.6 & 61.5 & 78.7 & 69.5 & 26 & 4 \\
\hline
\end{tabular}

As shown in table 1. Kosovo weather averages, we experience extreme heat and cold conditions for long durations (three months cold winter and three months hot summer), making passive design challenging.

\subsection{Comfort}

The human being, like other bodies, exchanges heat with its environment through conduction (by direct contact), convection (transported by air), radiation (mainly shortwave visual light and long-wave heat) and evaporation/condensation (heat released through change of state of water, also called latent heat). Factors influencing the heat balance are environmental, such as air and mean radiant temperatures, vapor pressure and air motion, but also individual, such as metabolic rate and clothing. The thermal equilibrium must be maintained within narrow limits for survival, and the range of comfort is even narrower.

\section{Architecture and simulation modeling relating to passive design}

Innovative architecture and scientific lessons learned have been captured in sophisticated comprehensive building energy simulation computer software systems.

Computer-aided design (CAD) is the use of computer systems to assist in the creation, modification, analysis, or optimization of a design [4].

Computer aided simulations employing ArchiCad was used for the orthographic and three-dimensional drawings and eco-designer tool to test energy performance of building in precise angles of orientation, appropriate design and dimensions of shading devices for all year round performance. 
Energy performance evaluation reports are highly customizable and can be used to help design decisions, illustrate client presentations, help investment decisions, provide input for the engineers to size the heating and cooling systems, or to provide performance data required by authorities.

The geometry and material properties of the building energy model can be shared with third party energy analysis software via a rich variety of data export formats.

Building Energy Modeling, offering a workflow that fulfills the most rigorous energy standards, delivering multiple thermal block-based, accurate, standard- compliant, dynamic energy analysis for any design stage, all building types, in any climate!

Architects can evaluate energy performance directly from GRAPHISOFT ArchiCAD, using its native energy evaluation infrastructure, ensuring quick evaluation even at the early design stages to support design decisions and client communication.

The building energy model geometry is automatically generated from the ArchiCAD BIM. ArchiCAD includes building material and glazing catalogues that list all energy-related physical properties of building structures and openings. The thermal characteristics are assigned to the skins of composite structures and to the openings, enabling accurate energy evaluation results for buildings of any size.

\section{Basic principles of passive design}

The scientific basis for Passive Building Design has been developed from a combination of climatology and thermodynamics. Basic principles of passive design are based on simple, proven approach. Passive design refers to an approach that discourages reliance on mechanical systems for heating, cooling and lighting and instead harnesses naturally occurring phenomenon such as the power of the sun, direction of wind and other climatic effects to maintain consistent indoor temperatures and occupant comfort. Factors influencing passive design are external and internal.

External factors: the site, location and solar orientation of the building, local sun path, the prevailing level of insulation. Internal factors: construction quality / materials, placement / size / type of openings and walls, and incorporation of solar-energy-storing thermal mass with heat capability.

While these factors may be directed toward any building, achieving an ideal optimized cost / performance solution requires careful, holistic, system integration engineering of these scientific principles.

By leveraging the natural environment, buildings that incorporate passive design can: help to reduce or even eliminate utility bills improve the comfort and quality of the interior environment reduce emissions associated with heating, cooling, mechanical ventilation and lighting reduce the need for mechanical systems, thereby reducing the resources required to manufacture these systems, as well as the costs associated with their purchase or operation make alternative energy systems viable.

\subsection{Building Energy Standards}

The most common energy efficiency standards for buildings are:

- Low Energy Buildings;

- Passive Houses;

- Zero Energy Buildings (ZEB) and Zero Carbon Buildings;

- Plus Energy Buildings;

- Green buildings.

Other types of buildings also aim at higher standards beyond the requirements in energy efficiency standards and building codes, for example, Intelligent Buildings, Sustainable Buildings.

Low energy buildings. This term is generally used to indicate that buildings have a better energy performance than the typical new building or the energy efficiency requirements in building regulation, and that the building hence will have a low energy consumption compared to a standard building.

Passive Houses. A passive house is a building in which a comfortable indoor climate can be obtained without a traditional heating or cooling system. A passive house make maximum exploitation of passive technologies (eventually adopting also some active solar technology), assuring a comfortable indoor climate during summer and winter without needing any conventional heating or cooling system. 
Compared to traditional building they use far less energy. In order to be a passive house a building must fulfill the following conditions:

- The building must use $15 \mathrm{kWh} / \mathrm{m} 2$ a or less in heating energy;

- The specific heat load for heating source at design temperature must be less than $10 \mathrm{~W} / \mathrm{m} 2$;

- With the building pressurized to $50 \mathrm{~Pa}$ by a blower door test, the building must not leak more air than 0,6 times the house volume per hour $(\mathrm{n} 50 \leq 0,6 / \mathrm{h})$;

- Total primary energy consumption 11 must not be more than $120 \mathrm{kWh} / \mathrm{m} 2 \mathrm{a}$.

- -Zero Energy Buildings (ZEB) is a residential or commercial building that do not use fossil fuels but only get all their required energy from solar energy and other. At the heart of the ZEB concept is the idea that buildings can meet all their energy requirements from low-cost, locally available, non-polluting, renewable sources.

As the current generation of electric storage technologies is limited, achieving a ZEB without the grid is almost impossible. A ZEB uses traditional energy sources such as the electric and natural gas utilities when on-site generation does not meet the loads. When the on-site generation is greater than the building's loads, excess electricity is exported to the utility grid.

Plus energy buildings are buildings that deliver more energy to the supply systems than they use. Over a year, these buildings produce more energy than they consume 1 .

Green buildings are those with increased energy efficiency, but at the same time reductions are made on water consumption, use of materials and assessment of the general impact on health and environment. Green buildings can include a long list of requirements including resources, indoor air-quality and requirements that all products for the building must come from a local region

\subsection{Design Considerations}

Historically, passive techniques were the only way to cool buildings, while heating could be obtained by burning wood or coal. There are now technical means that would allow building design to ignore the climate; but while this is technically possible, there are still good reasons to adopt passive techniques, not only economic, but also to promote environmental sustainability at both local and global levels. Passive and low energy design helps the building take advantage of the climate when it is advantageous, and protects the building from the climate when it is not. This requires good knowledge of local climate and a greater sophistication on the part of the designer. The designer must therefore have adequate tools for this sophisticated task of passive design.

Site planning and landscaping. Sites slope, elevation, orientation, vegetation and wind pattern play important role in increased summer cooling by wind and reduced radiation effects by shading. The process of site planning and landscaping have to be organized in these steps:

- Gather information about the site and who will use it.

- Prioritize needs and wants.

- Reflect on maintenance requirements.

- Establish a budget.

- Design the landscape space.

- Verify the shape and size of the spaces and how they relate to each other.

- Select the plants that will fill the landscape.

Trees in site can result in energy saving, reduction of noise and pollution, modification of temperatures and relative humidity and psychological benefits on humans. Trees with large plants mass having trunk exposed of branches up to the top level of window, deflect the outdoor wind downward and promote air motion in the occupancy zone inside the buildings. Further research is needed to identify suitable plant species in specific climatic regions. Trees can act balancing to window overhangs, as they are better for overcrowding low morning and afternoon sun, while overhangs are better barriers for high noon sunshine. Research shows that the cooling loads of a house can be reduced by $10 \%-40 \%$ by appropriate tree plantation.

Building shape, space \& orientation. In local regulations calculations are based on building shape factor that is defined with formula: $\mathrm{f}_{0}=\mathrm{A} / \mathrm{V}_{\mathrm{e}}$ - covering area quotient $\mathrm{A}\left(\mathrm{m}^{2}\right)$ and building heated area capacity Ve (m3). The shape of the building includes its main proportions, scale/volume, attachment etc. 
Buildings must be spaced to allow winds to reach the ventilation openings. In general, it is not desirable to site buildings within the wake of surrounding structures or landscaping. The terrain, surrounding vegetation and plans and layout of buildings may be used to "channelize the air flow" into the building. Buildings constructed on earth mounds or sloping sites of hills gets advantage of enhanced wind speeds. Air motion in a shielded building is less than that in an unobstructed building

Orientation of a building plays an important role in prevailing the total amount of solar radiation incident on the building envelope. Hence, for minimum solar heat gain by the building envelope, it is desired that the longer axis of building should lie along East-West direction. Further, the effect of orientation of a building on heat penetration through envelope also depends on the aspect ratio (length/breadth) of the building.

For a building with square plan (aspect ratio 1:1) and glass area equally distributed on all the four walls, the effect of orientation is nil, while for a rectangular building with aspect ratio 2:1, the fabric load is reduced by 30 per cent due to change in orientation from worst to best.

In areas where comfort is acquired mainly by air movement, it is important to orient the building according to prevailing winds. In regions where ambient temperature has greater influence on comfort than ventilation, orientation with respect to the sun is important. A north-south orientation of the main facades is preferable, since the summer sun penetrates facades and openings only marginally in these directions, while in winter when the path of the sun is lower, there is possibility of solar access.

Ideal building orientation may be constrained by municipal planning layout requirements. A building can still use passive design strategies through careful consideration of the placement of windows and the design features used for shading and ventilation.

As orientation is dictated by municipal planning, design becomes an important consideration - building design should acknowledge site limitations and compensate for them.

Even small changes in orientation and attention to details such as overhangs can be very effective.

\subsection{Structures - Insulation}

Thermal mass is a measure of a material's capability to absorb heating or cooling energy. Materials such as concrete or bricks are highly dense and require a lot of energy to be heated or cooled. On the other hand, materials such as timber are less dense and do not need to absorb much energy for smaller changes in temperature. The more energy it takes to affect a temperature change of the material, the higher the thermal mass. The time it takes for the material to store and then release the heat energy is referred to as the thermal lag.

Insulation is of great value when a building requires mechanical heating or cooling and helps reduce the space-conditioning loads. Location of insulation and its optimum thickness are very important. In hot climates, insulation is placed on the outer face (facing exterior) of the wall so that thermal mass of the wall is weakly coupled with the external source and strongly coupled with the interior.

Local regulations define conditions for new building project, respectively reconstruction or adaptation of the existing building. If the building is in harmony to regulations, then is considered to have accomplished important terms in the aspect of "thermal energy saving and protection", defined by local Law on Construction.

Use of $40 \mathrm{~mm}$ thick expanded polystyrene insulation on walls and vermiculite concrete insulation on the roof has brought down space-conditioning loads of the retreat building by about $15 \%$.

Materials - Insulation. Use of natural materials, local materials, recycled materials, are all passive design features that can also passively utilize energy sources. Over the lifespan of a building, insulation will always have a positive environmental impact by reducing operating energy. However, the ecological footprint of the material itself should also be taken into consideration. This is complicated to define because there are a lot of different factors to be considered. Insulation can also have a bearing on indoor environmental quality depending on the materials selected, and can have implications for air tightness.

Selecting Insulation Materials. Insulation can serve as more than just an energy barrier, providing fire resistance, humidity control, and noise reduction among other things. Many fiber-based materials, such as cellulose or wood fiber, are sensitive to water exposure - a common concern in Kosovo's climate. On the other hand, these materials can also act to modify humidity levels, which is particularly relevant for structures that are meant to breathe, such as those which use straw bales. 
Air tightness. It is imperative for a structure to have an airtight layer in order for insulation to be effective. There are several strategies for achieving a super tight building envelope.

Thermal Bridges. By local regulations Thermal bridge is defined as a little area (space) in building covering heated section through which heating flow changes because of material change, thickness or geometrical shape of it. A thermal bridge occurs where construction materials create a bridge between internal and external environments allowing a heat transfer to occur. Wherever possible, thermal bridges need to be avoided through the use of a thermal break. Thermal breaks are literally breaks inserted into the component (for instance in the window frame), which separate the exterior and interior materials.

Roof. The roof receives significant solar radiation and plays an important role in heat gain/losses, day lighting, and ventilation. Depending on the climatic needs proper roof treatment is very essential

External walls. Walls are a major part of the building envelope and receive large amounts of solar radiation. The heat storage capability and heat conduction property of walls are key to meeting desired thermal comfort conditions. The wall thickness, material, and finishes can be chosen based on the heating and cooling needs of the building. Appropriate thermal insulation and air cavities in walls reduce heat transmission into the building, which is the primary aim in a hot region.

Composite structures. Slab on grade and slab is a very common method to create thermal mass. Generally should be insulated from the ground below to avoid losing heat in the winter.

Table 2. Current standard required for insulation of walls, floors and roofs based on local technical regulation on thermal energy savings and thermal protection in building No.03/2009 compared with Passivhaus Standard

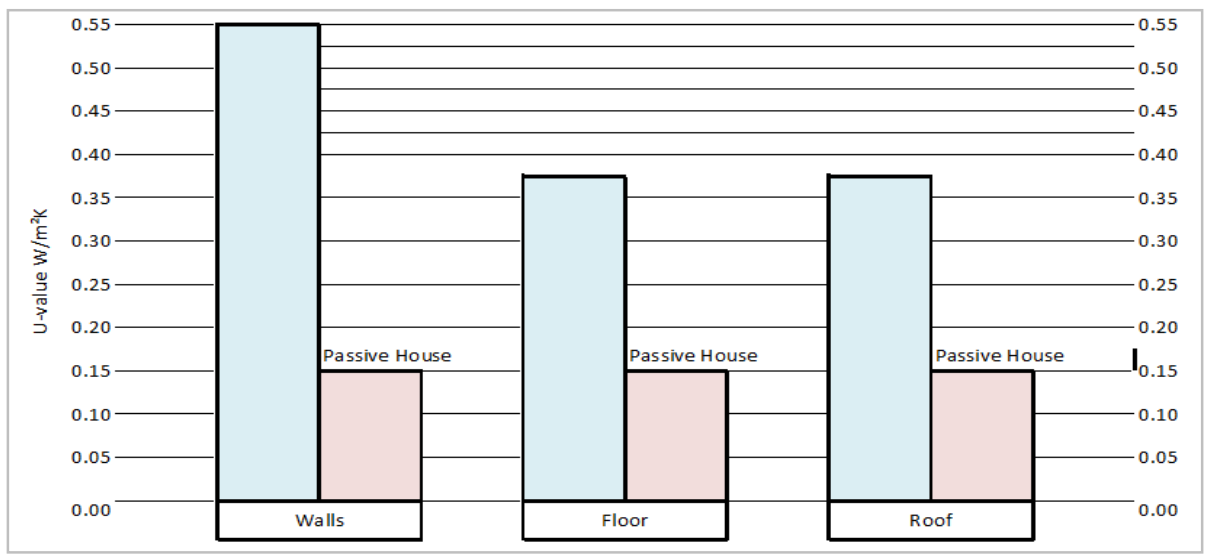

\subsection{Openings}

Windows (glazing). One of the most efficient ways to harness the power of the sun is through the use of suitable window technologies. Conventional buildings lose upwards of 50 percent of their heat through windows. At the same time, passive solar gain through windows is generally limited to just a few percent. In order to design windows that contribute to passive heating in the cooler winter months without an associated overheating risk in the summer, it is critical to balance location, size and thermal quality.

Thermal quality and style of window. The overall quality of a window is key to its performance and can be determined by the thermal quality of the glass and the frame. Further considerations are the solar heat gain coefficient of the glass and of the spacer material. The style of window will also have an effect on its performance. Slider windows may be poorer air barriers as the sealing system is harder to design. Fixed windows are permanently sealed but do not offer the benefits of ventilation. Hinged windows use compression seals that are more sturdy than slider windows but may still wear out. Issues arise when worn out seals are not replaced.

Location and Size of Windows. It is also important to remember that, in addition to having the lowest insulation value as a component of the building envelope, windows are also a source for thermal bridges. 
Therefore, an appropriate number of windows will mitigate unnecessary heat loss or gain. As a general rule of thumb, windows should not exceed $2 / 3$ of the envelope. In fact, due to the nature of thermal bridges, the number of individual windows should also be kept to a minimum - one slightly larger window is more efficient that two windows even if they equal the same area of window.

By local regulations involvement of window surface to the whole front surface is the quotient of window surface, balcony door and transparent elements (construction openings) in façade with total front surface (wall + windows,..). Roof window surface is added to heated sub roof window surface, and roof inclined surface to which windows are placed is added to the total front surface.

Shading. Appropriate use of shading can prevent too much heat from entering a building by shading the glass from direct sunlight. This is particularly important for the south elevation during the warm summer months. Shading strategies can include using overhangs, eaves, louvers and sunshades to regulate solar access.

\section{Recommendations}

\subsection{Social aspect:}

Improve the Effectiveness of Government Supervision of Building Construction Sector. Introduce of an environmental law course to the Kosovo university system. Information campaigns to professionals on necessity to incorporate passive design features and simulation modeling in a building design to minimize load on conventional systems (heating, cooling, ventilation and lighting). Expand and Strengthen the Political Support for Energy Efficiency

\subsection{Spatial and planning aspect:}

Based on local climate, researches and regulations the authorities must publish passive design toolkit suitable for specific locations.

The results from building physics course argues that concept suitable for one place may not be suitable for another, if the climatic conditions are different. Hence, being highly site specific, based on the climatic zones like hot and dry, warm and humid, cold and sunny, cold and dry, composite conditions etc., the selection of various methods, and the selection of buildings and the associated materials, has to be made [5].

\subsection{Environmental aspect:}

Use landscaping consistent with required amounts of shading at different times of the year - deciduous trees will offer shade in summer but access to solar heat in winter. Minimize unwanted shade to allow passive solar energy use. Select materials by balancing their relative strengths and weaknesses against environmental impact considerations.

\section{Conclusion}

Adapting the new concept of energy performance of buildings to present local practice combined with ancient methods of passive architecture tools in an efficient modern way is challenging for architects and other stakeholders in Kosovo building industry.

Law enforcement and information campaigns to owners or tenants of buildings on rational energy use and benefits from better energy performance of building will highlight necessity for adapting the new concept of energy performance of buildings by professionals.

New concept must be adapted by builders investors to change wrong behavior and present practice of builders promoting passive traditional methods in an efficient modern way using active technological 
tools in combination with ancient methods. Appropriate use of software's and these tools can greatly increase the energy efficiency of a building and reduce environmental impact.

Today with Computer-Aided Design (CAD) professionals can evaluate energy performance of building to assist in performance optimization from design stage until the end of life cycle.

Energy modeling, for instance using GRAPHISOFT ArchiCAD software, can help to determine when increasing insulation in a certain part of the structures of building will improve performance and when it can no longer make a difference.

The use of exterior vertical louvers in combination with natural ventilation (cross ventilation or only infiltration) was also analyzed in terms of thermal comfort. The results from simulation modeling indicate that closest to a comfortable condition for the situation in which horizontal louvers were applied. The second best situation was the one with only vertical louvers.

The cost effective proof of concept is easy, but cultural assimilation into architecture, construction trades, and building-owner decision making in Kosovo is difficult to change. Adapting new concept, using appropriate technological tolls (software's) will increase the skills and ability of architects to develop awareness by energy models designs to promote benefits of building passive buildings or environmentally responsive buildings in identified local climatic parameters within a site.

Passive design method used in the past can be practical to contemporary buildings. However, each architectural element must integrate suitable changes according to the environment. This approach brings about not only a positive effect on the living environment through passive design solutions but also great importance for culture and society.

\section{References}

1. de Schiller S. and Evans J. M. (2006). Training architects and planners to design with urban microclimates. In S. S. Olweny M., Best Practice in Environmental and Sustainable Architecture (Vols. Vol. 30, No.3). Uganda: Best Practices.

2. Givoni B. (1991). Impact of planted areas on urban environment quality: a review. Atmosph. Environ.;25:289-291.

3. Gut, P. \& Ackerknecht, D. 1993. Climate Responsive Building: Appropriate Building Construction in Tropical and Subtropical Regions. Switzerland: SKAT.

4. Narayan, K. Lalit (2008). Computer Aided Design and Manufacturing. New Delhi: Prentice Hall of India. p. 3. ISBN 812033342X.

5. Orosa JA. (2012). New methodology to define probability of buildings energy consumption. Energ. Educ. Sci. Technol. Part-A 2012;28:891-902.

6. Raeissi,S. \& Taheri, M. 1999. Energy Saving by Proper Tree Plantation. Building and Environment, 34(1999): 565-570.

7. Watson, D. \& Labs, K. 1983. Climatic Building Design: Energy-Efficient Building Principles and Practice. New York: McGraw-Hill. 